\title{
A Study of Thyroid Function in Partial Thyroxine-Binding Globulin Deficiency
}

\author{
Jae Won Lee', Jang Yong Jin'1, Jungho Lee², Dong Hwan Lee², Yong Hee Hong' \\ 'Department of Pediatrics, Soonchunhyang University Bucheon Hospital, Soonchunhyang University College of Medicine, Bucheon; ${ }^{2}$ Department of Pediatrics, \\ Soonchunhyang University Seoul Hospital, Soonchunhyang University College of Medicine, Seoul, Korea
}

\begin{abstract}
Objective: It is generally thought that thyroxine-binding globulin (TBG)-deficient individuals are euthyroid and do not require treatment. However, there have been case reports of TBG deficiency combined with hypothyroidism. The purpose of this study was to investigate the relationship between TBG deficiency and thyroid function.

Methods: We reviewed the medical records of 32 patients diagnosed with TBG deficiency between 1997 and 2008 in Soonchunhyang University Seoul Hospital. All were partial TBG deficiency. Eighteen patients had combined hypothyroidism, and 14 patients had normal thyroid function. We compared the TBG, thyroid-stimulating hormone, free thyroxine, and total triiodothyronine levels between these 2 groups. Eighteen patients with TBG deficiency with hypothyroidism started thyroxine medication and continued for 2-3 years. After, they were followed up with thyroid function tests after discontinuing medication for 4 weeks at 2-3 years of age. Results: The TBG level in TBG deficiency with hypothyroidism patients was significantly lower than that in TBG deficiency with normal thyroid function $(4.43 \pm 2.22 \mathrm{mg} / \mathrm{L}$ vs. $6.23 \pm 1.81 \mathrm{mg} / \mathrm{L} ; \mathrm{P}=0.02)$. The percent TBG compared with normal mean TBG level according to age in the hypothyroidism patients was also significantly lower than that of patients with normal thyroid function $(13.42 \% \pm 6.92 \%$ vs. $19.08 \% \pm 4.87 \% ; \mathrm{P}=0.014)$. Sixteen of 18 patients diagnosed with TBG deficiency with hypothyroidism showed persistent hypothyroidism at 2-3 years of age.

Conclusion: We conclude that TBG-deficient patients should be observed closely and undergo thyroid function testing in order not to miss hypothyroidism. More investigations of TBG deficiency and thyroid function are needed in the future.
\end{abstract}

Keywords: Thyroxine-binding globulin; Hypothyroidism; Thyroid function tests; Thyroxine

\section{INTRODUCTION}

Thyroid hormone is essential to the human body, affecting the cardiovascular, respiratory, gastrointestinal, muscular, nervous, endocrine, and metabolic systems [1]. Screening with thyroid function tests is important in children, and it is especially important to rule out hypothyroidism in neonates.

Thyroid hormone binding proteins have a very important role in thyroid hormone action, serving as an extrathyroidal reservoir of the hormones to ensure an uninterrupted supply of thyroid hormones is available to various target tissues of the body [2]. Three thyroid hormone binding proteins are present in our body, thyroxine (T4)-binding globulin (TBG), albumin, and transthyretin [2]. TBG is the major transport protein and binds to approximately $70-75 \%$ of T4 and $65-70 \%$ of triiodothyronine (T3) [2].
TBG is a $54-\mathrm{kDa}$ acidic glycoprotein synthesized by the liver [3]. It is composed of a single polypeptide chain of 395 amino acids and is encoded by a single gene copy located on the long arm of the human X-chromosome (Xq22.2) [3]. Inheritance of TBG abnormalities, including TBG deficiency and TBG excess, follows an X-linked pattern [3].

Clinically, TBG defects are classified as complete TBG deficiency, partial TBG deficiency, and TBG excess [4]. Complete TBG deficiency is defined as undetectable TBG in serum, that is, $<0.03 \%$ of the normal mean; with the current limit of detection being $5 \mathrm{ng} /$ $\mathrm{dL}(0.05 \mathrm{mg} / \mathrm{L})$ [4]; the prevalence is approximately 1 in 15,000 newborn boys [4]. Partial TBG deficiency is defined as a TBG level lower than $50 \%$ of the normal range [4]. Partial TBG deficiency is the most common form of inherited TBG deficiency with a prevalence of 1 in 4,000 newborns [4]. 
Infants born with TBG deficiency were thought to be euthyroid and therefore did not require treatment. However, not all TBG-deficient individuals are euthyroid. The first case report of an infant diagnosed with TBG deficiency after newborn screening demonstrated persistent elevation of thyroid-stimulating hormone (TSH) and abnormally low free T4 levels appeared in 1999 in the United States [5]. Patient's TSH level was $19 \mu \mathrm{IU} / \mathrm{mL}$, free T4 level was 0.49 $\mathrm{ng} / \mathrm{dL}$ and a TBG level was below $5 \mathrm{mg} / \mathrm{dL}$ at age day 21th [5]. The patient was diagnosed partial TBG deficiency combined hypothyroidism [5]. At 5 years of age, after withdrawal of medication for 8 weeks, the patient's TSH level increased, and T4 medication was resumed [5]. In Korea, a similar case was first reported in 2002 [6]. A child diagnosed with congenital hypothyroidism was identified with TBG deficiency at 22 months of age [6]. After withdrawal of T4 medication at age 26 months for 6 weeks, his TSH level (65.4 $\mu \mathrm{IU} / \mathrm{mL})$ increased and free T4 level $(0.67 \mathrm{ng} / \mathrm{dL})$ decreased, and therefore, he could not stop T4 medication [6]. TBG level was 0.01 $\mathrm{mg} / \mathrm{L}$, diagnosed complete TBG deficiency combined hypothyroidism. The aim of the present study was to investigate the relationship between TBG deficiency and thyroid function.

\section{MATERIALS AND METHODS}

In Korea, TSH level is usually checked in neonatal screening test. In some institute, T4 level is checked simultaneously with TSH level, and we selected patients in these patients. From 1997 and 2008, TBG level was checked in patients who had normal TSH level and low T4 level in Soonchunhyang University Seoul Hospital. Patients who had specific birth history including preterm, low birth weight, neonate intensive care admission history, any congenital disease and medication history were excluded in this study. Also patients who had specific maternal history including maternal disease history, medication history were also excluded. Conclusively, 32 patients were included in this study and they were diagnosed partial TBG deficiency. We retrospectively analyzed their medical records. Eighteen patients had abnormal thyroid function, 17 patients were boys and 1 patient was girl. Fourteen patients had normal thyroid function, 13 patients were boys and 1 patient was girl. All 32 patients had confirmed diagnosis at before 2 months old. We compared the TBG, TSH, free T4, and total T3 levels between these 2 groups. Thyroid ultrasonography (USG) and thyroid scan findings and thyroglobulin (TG) levels were evaluated only in the combined hypothyroidism group. Eighteen patients with par- tial TBG deficiency with hypothyroidism started T4 medication (10-15 $\mu \mathrm{g} / \mathrm{kg} / \mathrm{day})$, and we followed up with thyroid function tests after discontinuing medication for 4 weeks at 2-3 years of age. TBG (BRAHMS, Hennigsdorf, Germany), TG (Cisbio Bioassays, Codolet, France), TSH (Diasorin, Stillwater, MN, USA), free T4 (Immunotech, Prague, Czech Republic), and total T3 (Cisbio Bioassays) levels were measured by radioimmunoassay.

We defined partial TBG deficiency as lower than $50 \%$ of the normal mean TBG level according to the patient's age [4]. Normal TBG levels were based on the following criteria: age $<4$ weeks, 26.1-42.5 mg/L (mean, $34.3 \mathrm{mg} / \mathrm{L}$ ); 4 weeks to < 1 year, 15.6-43.2 $\mathrm{mg} / \mathrm{L}$ (mean, $29.4 \mathrm{mg} / \mathrm{L}$ ); and 1-15 years, 14.7-36.3 mg/L (mean, $25.5 \mathrm{mg} / \mathrm{L})$.

We used SPSS ver. 14.0K for Windows (SPSS Inc., Chicago, IL, USA) to conduct the paired t-test, Student t-test, and Pearson's correlation test for analysis. All P-values $<0.05$ were considered statistically significant.

\section{RESULTS}

Table 1 shows the mean TBG level in partial TBG deficiency with hypothyroidism group was significantly lower than that in partial TBG deficiency with normal thyroid function group (4.43 $\pm 2.22 \mathrm{mg} / \mathrm{L}$ vs. $6.23 \pm 1.81 \mathrm{mg} / \mathrm{L} ; \mathrm{P}=0.02$ ). The percent $\mathrm{TBG}$ compared with normal mean TBG level according to age in the hypothyroidism patients also was significantly lower than that of patients with normal thyroid function $(13.42 \pm 6.92 \mathrm{mg} / \mathrm{L}$ vs. 19.08 $\pm 4.87 \mathrm{mg} / \mathrm{L} ; \mathrm{P}=0.014)$. TG level in hypothyroidism group was $51.21 \pm 28.66 \mathrm{ng} / \mathrm{mL}$ (reference range, 10.6-92.0 ng/mL).

Fig. 1 shows there were no significant correlations between TSH level and percent TBG compared with normal mean TBG level according to age in patients with hypothyroidism and normal thyroid function $(\mathrm{P}=0.504$ and $\mathrm{P}=0.107$, respectively).

Thyroid USG findings of patients diagnosed with partial TBG deficiency with hypothyroidism were normal in 14 patients (77.7\%) but showed hypoplasia in 3 patients (16.7\%) and a nodule in 1 patient (5.6\%) (Table 2). Thyroid scan findings showed decreased uptake in 13 patients (72.2\%), agenesis in 4 patients (22.2\%), and enlargement in 1 patient (5.6\%) (Table 3 ).

Sixteen patients (all but patients 17 and 18) could not stop T4 medication because after withdrawal of medication for 4 weeks at 2-3 years old, their TSH levels increased or their free T4 levels decreased (Table 4). Thyroid USG findings were normal in 12 patients 
Table 1. Thyroid function in patients with partial TBG deficiency with hypothyroidism and partial TBG deficiency with normal thyroid function at diagnosis

\begin{tabular}{|c|c|c|c|}
\hline Lab finding at diagnosis & TBG deficiency with hypothyroidism $(n=18)$ & TBG deficiency with normal thyroid function $(n=14)$ & P-value \\
\hline $\mathrm{TBG}$ (mg/L) & $4.43 \pm 2.22(0.5-7.48)$ & $6.23 \pm 1.81(4.5-9.67)$ & $0.02^{\text {a) }}$ \\
\hline $\begin{array}{l}\text { Percent (\%) TBG compared with normal } \\
\text { mean TBG level by age }\end{array}$ & $13.42 \pm 6.92(1.46-25.10)$ & $19.08 \pm 4.87(13.12-28.19)$ & $0.014^{a)}$ \\
\hline Thyroid-stimulating hormone $(\mu \mathrm{lU} / \mathrm{mL})$ & $10.87 \pm 1.69(6.37-30.8)$ & $3.35 \pm 0.40(0.02-5.19)$ & $0.001^{\mathrm{al}}$ \\
\hline Free thyroxine (ng/dL) & $1.39 \pm 0.99(0.42-2.82)$ & $2.79 \pm 1.08(1.24-3.82)$ & $0.001^{\text {al }}$ \\
\hline Total triiodothyronine (ng/dL) & $60.19 \pm 22.27(34.21-104.38)$ & $59.43 \pm 18.15(37.78-91.65)$ & 0.919 \\
\hline Thyroglobulin (ng/mL) & $51.22 \pm 28.66(11.9-120.63)$ & NA & NA \\
\hline Age at diagnosis (day) & $35.83 \pm 14.61(14-58)$ & $35.14 \pm 10.92(17-58)$ & 0.884 \\
\hline Sex (male:female) & $17: 1$ & $13: 1$ & 0.932 \\
\hline
\end{tabular}

Values are presented as mean \pm standard deviation (reference range).

TBG, thyroxine-binding globulin; NA, not applicable.

al $<0.05$ is considered statistically significant.

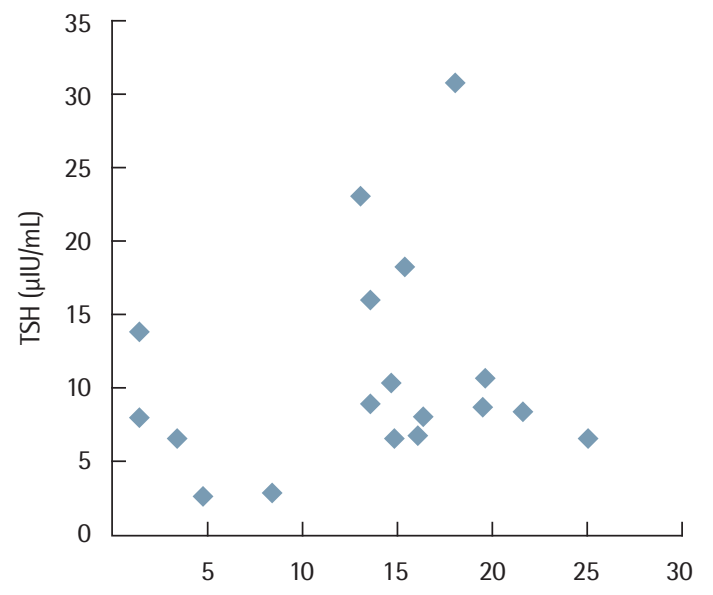

Percent (\%) of TBG compared with normal mean TBG level by age

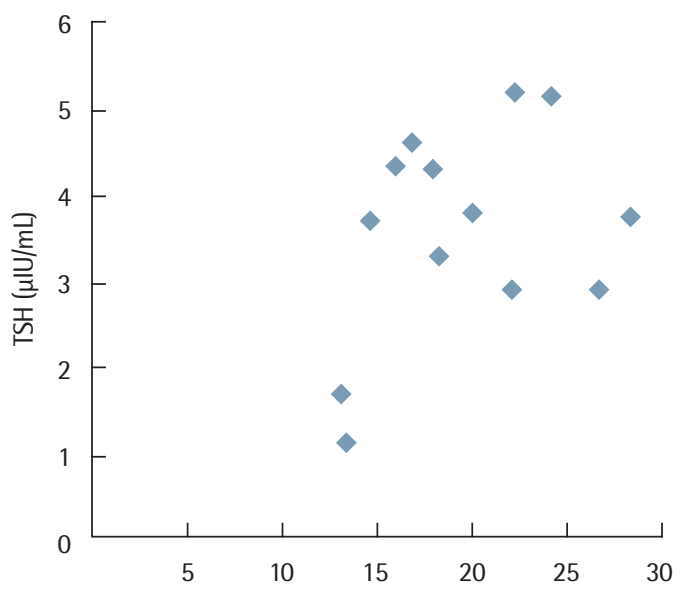

Percent (\%) of TBG compared with normal mean TBG level by age

Fig. 1. (A) Rank correlation between percent (\%) of TBG compared with normal mean TBG level by age and thyroid-stimulating hormone level in 18 patients, diagnosed TBG deficiency with congenital hypothyroidism $(r=0.169, P=0.504)$. (B) Fourteen patients, diagnosed TBG deficiency with normal thyroid function $(r=0.450$, $P=0.107)$. TBG, thyroxine-binding globulin.

Table 2. Thyroid ultrasonography findings of patients diagnosed with partial thyroxine-binding globulin deficiency with hypothyroidism at diagnosis $(n=18)$

\begin{tabular}{lc}
\hline Thyroid ultrasonography finding & No. of patients (\%) \\
\hline Normal & $14(77.7)$ \\
Hypoplasia & $3(16.7)$ \\
Nodule & $1(5.6)$ \\
\hline
\end{tabular}

(66.6\%) but showed nodules in 3 patients (16.7\%) and hypoplasia in 3 patients $(16.7 \%)$ at $2-3$ years old age after stop T4 medication. Thyroid scan findings showed decreased uptake in all but 1 patient.

\section{DISCUSSION}

Hypothyroidism in severe TBG deficiency is thought to be caused by exposure of the hypothalamus/pituitary to abnormal fluctua-
Table 3. Thyroid scan findings of patients diagnosed with partial thyroxinebinding globulin deficiency with hypothyroidism at diagnosis $(n=18)$

\begin{tabular}{lc}
\hline Thyroid scan finding & No. of patients (\%) \\
\hline Decreased uptake & $13(72.2)$ \\
Agenesis & $4(22.2)$ \\
Diffuse enlargement & $1(5.6)$ \\
\hline
\end{tabular}

tions in serum free T4 concentrations and the resulting increased fluctuation and probably net secretion of TSH (despite normal random TSH levels) [5]. The inability to sustain consistent and/or normal levels of free T4 leads to a state of compensated hypothyroidism [5]. The importance of TBG in maintaining constant levels of free thyroid hormone is also indirectly supported by findings of elevated TG levels in patients with TBG deficiency [7]. In our study, we did not check TG levels of patients with normal thyroid function 
Lee JW, et al. • Thyroid Function in TBG Deficiency

Table 4. Laboratory findings of partial TBG deficiency with hypothyroidism at 2-3 years of age after withdrawal of T4

\begin{tabular}{|c|c|c|c|c|c|c|}
\hline \multirow{2}{*}{ Patient } & \multirow{2}{*}{ Sex } & \multirow{2}{*}{$\begin{array}{l}\text { Follow-up \% TBG compared with } \\
\text { normal mean TBG level by age }\end{array}$} & \multicolumn{2}{|c|}{ Follow-up after stopping T4 medication for 4 weeks } & \multirow{2}{*}{ Thyroid ultrasonography } & \multirow{2}{*}{$\begin{array}{l}\text { Thyroid scan uptake } \\
\text { (normal range, 1.7-4.9) }\end{array}$} \\
\hline & & & Thyroid-stimulating hormone ( $\mu \mathrm{lU} / \mathrm{mL})$ & Free T4 (ng/dL) & & \\
\hline 1 & M & 3.92 & 8.04 & 0.7 & Normal & 0.77 \\
\hline 2 & M & 8.20 & 7.06 & 0.81 & Nodules, both thyroids & 0.6 \\
\hline 3 & M & 14.59 & 6.28 & 0.82 & Nodules, both thyroids & 1.1 \\
\hline 4 & $\mathrm{~F}$ & 17.69 & 10.92 & 1.07 & Hypoplasia & 1.3 \\
\hline 5 & M & 25.18 & 8.02 & 0.91 & Hypoplasia & 0.7 \\
\hline 6 & M & 25.37 & 7.04 & 0.70 & Normal & 0.6 \\
\hline 7 & M & 27.76 & 10 & 1.23 & Normal & 0.4 \\
\hline 8 & M & 18.39 & 11.2 & 1.84 & Normal & 0.6 \\
\hline 9 & $M$ & 24.00 & 9.19 & 1.91 & Nodule, left thyroid & 0.7 \\
\hline 10 & $M$ & 27.49 & 11 & 1.40 & Normal & 0.6 \\
\hline 11 & $M$ & 23.80 & 7 & 1.3 & Normal & 1.2 \\
\hline 12 & M & NA & 27.15 & 0.79 & Normal & 2.7 \\
\hline 13 & $\mathrm{~F}$ & 15.29 & 5.07 & 1.20 & NA & 0.53 \\
\hline 14 & M & 20.31 & 6.73 & 1.20 & Normal & 0.9 \\
\hline 15 & $M$ & 22.58 & 5.31 & 1.29 & Normal & 0.4 \\
\hline 16 & M & 8.27 & 3.04 & 0.76 & Hypoplasia & 1.1 \\
\hline 17 & M & 24 & 5 & 1.12 & Normal & 0.8 \\
\hline 18 & $M$ & 29.02 & 4.67 & 2.13 & Normal & 0.5 \\
\hline
\end{tabular}

Patients 17 and 18 had normal thyroid function after withdrawal of T4 medication for 4 weeks.

TBG, thyroxine-binding globulin; T4, thyroxine; M, male; F, female; NA, not applicable.

who were diagnosed with TBG deficiency. Therefore, we could not compare TG levels between the 2 groups. Another mechanism is thought to be impaired function of the buffering action of TBG in which TBG binds or releases T4 to normalize free T4 levels when they are increased or decreased, respectively [8].

There are two notable findings in our study. One is that the TBG level and percent TBG compared with the normal mean TBG level in patients with partial TBG deficiency were significantly lower in those with hypothyroidism than in those with normal thyroid function. From this finding, if congenital hypothyroidism was caused by TBG deficiency, we can carefully hypothesize that lower the TBG level, more chance of occurring hypothyroidism. The other is that like the 2 case reports mentioned in the 'Introduction' [5,6], 16 of 18 patients diagnosed with TBG deficiency with hypothyroidism showed persistent hypothyroidism at 2-3 years of age after withdrawal of T4 medication, a high percentage even though the patient group was not large. TSH level was not more increased when TBG level was lower than other in both hypothyroidism group and normal thyroid function group.

So far, there are no broad studies of association between thyroid function and TBG deficiency including clinical research and epidemiological research. Only a few cases have been reported, and some genetic studies of TBG deficiency have also been reported.

Female of 16 months old was reported as TBG deficiency with hypothyroidism in Japan in 1975 [9]. The patient had ectopic thyroid gland at sublingual area, no thyroid gland in normal position [9]. TSH level was upper than $500 \mu \mathrm{IU} / \mathrm{mL}$, total T4 level was 1.4 $\mu \mathrm{g} / \mathrm{dL}$, and TBG binding capacity was $7.8 \mu \mathrm{g} / \mathrm{dL}$ (normal range, 14 to $21 \mu \mathrm{g} / \mathrm{dL}$ ) [9]. The author asserted that TBG deficiency just simply combined hypothyroidism in the patient [9].

Two cases of adult men with hypothyroidism combined with complete TBG deficiency were reported in Taiwan in 2003 [10]. One was diagnosed with hypothyroidism at 45 years of age and the other at 47 years of age, and both were negative for all thyroid antibodies [10]. This was the first report of complete TBG deficiency due to TBG gene mutations on chromosome Xq22 in Taiwan [10].

There was another case report in Korea in 2005 of two male neonates diagnosed with complete TBG deficiency concluded as a single-nucleotide deletion resulting in a frameshift [11]. Both neonates had normal thyroid function [11]. Two families with X-linked complete TBG deficiency without mutations in the coding or promoter regions of the TBG gene were reported in 2002 in the United States [3]. Both families showed euthyroid function and had undetectable serum TBG. Intragenic A/G polymorphism was identified in one 
family, and a $\mathrm{G}$ to A substitution in 5 base pairs was discovered in the other family. Case report of partial TBG deficiency caused by a mutation in the signal peptide was first reported in 2004 in United States [12]. Reported woman was found to have TBG level $15 \mathrm{mg} / \mathrm{L}$ (normal range, 17 to $36 \mathrm{mg} / \mathrm{L}$ ) at 18 years old, incidentally. At the same time, Total T4 level was measured $44 \mathrm{nmol} / \mathrm{L}$ (normal range, 64 to $161 \mathrm{nmol} / \mathrm{L}$ ), TSH level $2.7 \mathrm{mIU} / \mathrm{L}$ (normal range, 0.4 to 5.5 $\mathrm{mIU} / \mathrm{L}$ ), so the woman started treatment with $125 \mu \mathrm{g}$ levothyroxine daily [12]. In 2014, one family group with a TBG partial deficiency by a novel mutation in Serpina7 gene that was coincident with a mutation in transthyretin (TTR) gene that increased affinity of TTR for T4 was first reported in Argentina [13]. Propositus was 55 years old man, who had thyroidectomy at 30 years ago and had levothyroxine medication. His TBG level was lower than $3 \mathrm{mg} / \mathrm{L}$, and his thyroid function test was normal (TSH level $0.89 \mu \mathrm{IU} / \mathrm{mL}$ and free T4 $1.02 \mathrm{ng} / \mathrm{dL}$ ). Seven members of his family were evaluated of same mutation of propositus, and 5 out of them had same mutation. And 3 out of them had low TBG level $(<3 \mathrm{mg} / \mathrm{L}, 3.6 \mathrm{mg}$ / $\mathrm{L}$, and $7.8 \mathrm{mg} / \mathrm{L}$ each), but there thyroid function test were normal.

We did not include a genetic study of partial TBG deficiency, and we could not accurately determine whether the congenital hypothyroidism was caused by TBG deficiency or the TBG deficiency was simply coincidentally combined in the hypothyroidism patients. If hypothyroidism was due to TBG deficiency in our studied patients, secretion of TSH level was may be affected by fluctuation of free T4 level or impaired function of buffering action of TBG or both. And we did not include TBG level of patients who had normal TSH level and normal T4 level. So we could not compare TBG level between these two groups.

Most of the patients in our study showed mild hypothyroidism. We carefully insist that it is important to rule out TBG deficiency if TSH level is slightly increased in neonate or infant. And reversibly, it is more important that TBG-deficient patients should be observed closely and undergo thyroid function testing in order to not miss the hypothyroidism. Significance of this study is that it was first trial of investigating thyroid function in partial TBG deficiency. More investigations of TBG deficiency and hypothyroidism, including genetic studies, are needed in the future. Specially, from genetic study, correlation between genotype and phenotype (i.e., thyroid function) should be considered.

\section{CONFLICT OF INTEREST}

No potential conflict of interest relevant to this article was reported.

\section{REFERENCES}

1. Schmaltz C. Thyroid hormones in the neonate: an overview of physiology and clinical correlation. Adv Neonatal Care 2012;12:217-22.

2. Bhatkar SV, Rajan MG, Velumani A, Samuel AM. Thyroid hormone binding protein abnormalities in patients referred for thyroid disorders. Indian J Med Res 2004;120:160-5.

3. Reutrakul S, Dumitrescu A, Macchia PE, Moll GW Jr, Vierhapper H, Refetoff S. Complete thyroxine-binding globulin (TBG) deficiency in two families without mutations in coding or promoter regions of the TBG genes: in vitro demonstration of exon skipping. J Clin Endocrinol Metab 2002;87:1045-51.

4. Refetoff S. Abnormal thyroid hormone transport [Internet]. South Dartmouth (MA): Thyroid Disease Manager; 2012 [cited 2015 Apr 1]. Available from: http://www.thyroidmanager.org/chapter/abnormal-thyroidhormone-transport/.

5. Carrel AL, Allen DB. Persistent infantile hypothyroidism attributable to thyroxine-binding globulin deficiency. Pediatrics 1999;104(2 Pt 1):312-4.

6. Lee DC, Lee SH, Yu JH. A case of thyroxine binding globulin deficiency with hypothyroidism. J Korean Pediatr Soc 2002;45:796-9.

7. Refetoff $S$. Inherited thyroxine-binding globulin abnormalities in man. Endocr Rev 1989;10:275-93.

8. Robbins J. Thyroid hormone transport proteins and the physiology of hormone binding. In: Braverman LE, Utiger RD, editors. Werner \& Ingbar's the thyroid: a fundamental and clinical text. 8th ed. Philadelphia (PA): Lippincott Williams \& Wilkins; 2000. p. 105-20.

9. Niimi H, Sasaki N. Familial thyroxine-binding globulin deficiency in a patient with congenital hypothyroidism. Endocrinol Jpn 1975;22:35-8.

10. Su CC, Wu YC, Chiu CY, Won JG, Jap TS. Two novel mutations in the gene encoding thyroxine-binding globulin (TBG) as a cause of complete TBG deficiency in Taiwan. Clin Endocrinol (Oxf) 2003;58:409-14.

11. Park SJ, Suh JS, Jung MH, Lee HJ, Suh BK, Lee WB, et al. A single nucleotide deletion resulting in frameshift in two Korean neonates with thyroxine-binding globulin deficiency. Korean J Pediatr 2005;48:1252-5.

12. Fingerhut A, Reutrakul S, Knuedeler SD, Moeller LC, Greenlee C, Refetoff $\mathrm{S}$, et al. Partial deficiency of thyroxine-binding globulin-Allentown is due to a mutation in the signal peptide. J Clin Endocrinol Metab 2004;89: 2477-83.

13. Sklate RT, Olcese MC, Maccallini GC, Sarmiento RG, Targovnik HM, Rivolta CM. Novel mutation p.A64D in the Serpina7 gene as a cause of partial thyroxine-binding globulin deficiency associated with increases affinity in transthyretin by a known p.A109T mutation in the TTR gene. Horm Metab Res 2014;46:100-8. 